\title{
Comparative Insight into the Interfacial Phase Evolutions during Solution Treatment of Dissimilar Friction Stir Welded AA2198-AA7475 and AA2198-AA6013 Aluminum Sheets
}

\author{
Mohammad Reza Jandaghi ${ }^{1, *(\mathbb{D}}$, Hesam Pouraliakbar ${ }^{2}\left(\mathbb{D}\right.$, Abdollah Saboori $^{3}$, Sun Ig Hong ${ }^{2}$ (D) \\ and Matteo Pavese ${ }^{1}$ (D)
}

Citation: Jandaghi, M.R.;

Pouraliakbar, H.; Saboori, A.; Hong, S.I.; Pavese, M. Comparative Insight into the Interfacial Phase Evolutions during Solution Treatment of

Dissimilar Friction Stir Welded AA2198-AA7475 and AA2198AA6013 Aluminum Sheets. Materials 2021, 14, 1290. https://doi.org/ $10.3390 /$ ma14051290

Academic Editors: Damjan Klobcar and Andrey Belyakov

Received: 23 January 2021

Accepted: 3 March 2021

Published: 8 March 2021

Publisher's Note: MDPI stays neutral with regard to jurisdictional claims in published maps and institutional affiliations.

Copyright: (c) 2021 by the authors. Licensee MDPI, Basel, Switzerland. This article is an open access article distributed under the terms and conditions of the Creative Commons Attribution (CC BY) license (https:/ / creativecommons.org/licenses/by/ $4.0 /)$.
1 Department of Applied Science and Technology, Politecnico di Torino, Corso Duca Degli Abruzzi 24, 10129 Torino, Italy; matteo.pavese@polito.it

2 Energy Functional Materials Laboratory (EFML), Department of Materials Science and Engineering, Chungnam National University, Daejeon 305764, Korea; hpouraliakbar@cnu.ac.kr (H.P.); sihong@cnu.ac.kr (S.I.H.)

3 Department of Management and Production Engineering (DIGEP), Politecnico di Torino, Corso Duca Degli Abruzzi 24, 10129 Torino, Italy; abdollah.saboori@polito.it

* Correspondence: mohammadreza.jandaghi@polito.it

\begin{abstract}
In the current research, dissimilar friction stir welded (FSW) sheets of AA2198-AA7475 and AA2198-AA6013 were solution treated at $460-580{ }^{\circ} \mathrm{C}$ for $1 \mathrm{~h}$. Annealing at $580{ }^{\circ} \mathrm{C}$ led to complete degradation of both dissimilar weldments from the AA2198 side. According to the microstructure inspection, solution treatment triggered abnormal grain growth within the stir zone (SZ), and applying higher treatment temperatures enhanced the fraction of transformed grains. SEM analysis revealed that the pre-melting of grain boundaries (GBs) over $540{ }^{\circ} \mathrm{C}$ encouraged the diffusion of solute atoms to the GBs. The massive diffusion of $\mathrm{Cu}$ to the GBs led to the formation of $\mathrm{Cu}$-rich eutectic phases in AA7475 and AA2198 and dense Cu-rich particles in AA6013. In the meantime, the diffusion of Mg and Zn to the GBs of AA7475 and Fe and Si to the GBs of AA6013 eventuated in the formation of coarse particles at the GBs which, in return, attenuated the bonding adhesion of the grains at SZ. The formation of remarkable $\mathrm{Cu}$-rich phases in the pre-melted regions and significant contraction of the eutectic phase while cooling as well as the formation of particles at GBs resulted in intergranular failure of the joints from the AA2198 side of the SZ.
\end{abstract}

Keywords: friction stir welding (FSW); aluminum alloy; microstructure; grain boundary (GB); premelting; diffusion; failure

\section{Introduction}

Owing to desired characteristics such as high strength and corrosion resistance, aluminum alloys have found an extensive range of applications in the aerospace and automotive industries [1,2]. For instance, in the aerospace sector, large aluminum sheets must be assembled to achieve the final huge structures such as aircraft $[3,4]$. There are multiple cases of employing AA2XXX and AA7XXX in the wing structure [5]. However, joining these alloys by traditional fusion welding techniques, such as gas tungsten arc welding, electron beam welding, or laser welding, usually promotes a wide range of defects such as cracking, residual stresses, porosities, liquefaction, and softening of the heat-affected zone (HAZ) in the joints [6]. Hence, friction stir welding (FSW), as a solid-state metal joining method, has been developed as a promising way to produce defect-free joints with higher quality $[7,8]$. In this technique, a pin extending from larger shoulder inserts in abutting edges of the workpieces and rotary moves between two sheets along the welding surfaces by a certain angle. This rotational and translational movement of the tool makes a frictional heat required to plasticize the materials for semi-solid joining [9]. Depending on the process parameters such as rotation and travel speed, pin geometry, and operating 
conditions, the temperature in the stir zone (SZ) could vary from $60 \%$ up to $95 \%$ of the melting point of alloy $[10,11]$. The remarkable temperature gradient from the center of the weld line to the base metals (BMs) promotes different microstructure zone consequences in precipitation dissolution or precipitation coarsening in the treatable alloys [12]. The subsequent effect of this phenomenon would be undesirable, such that even post-weld aging cannot recover the spread defects. To attain a high-strength weldment in dissimilar joints between the aluminum alloys, it is necessary to optimize the process parameters (rotation speed, pin angle, and transverse speed) and post-weld treatment (annealing time and temperature, as well as cooling rate) to ameliorate the dissolution process while suppressing the particles coarsening.

Tunneling defects [13] and kissing bonds [14] are the most prevalent imperfections reported for FSWed joints. Accordingly, kissing bonds reduce fatigue life with a minor impact on the tensile strength. A low rotational speed or a high travel speed could encourage a tunneling defect and kissing bond. It is well documented that insufficient heat input eventuates in faulty stir and incomplete softening of the materials beneath the shoulder. Meanwhile, a synergy of great rotational and traverse speed could make a cavity under the weld-line due to abnormal stirring. Usually, for a set of optimized FSW parameters, increasing the travel speed besides constant rotational rate improves the mechanical properties of the joint, while increasing the rotational speed generates higher heat input and attenuates the mechanical strength [15].

Post-weld heat treatment (PWHT) is usually employed to restore a significant portion of the lost mechanical strength of the joints, and several studies have investigated the effect of PWHT on the performance of welded sheets [16,17]. Previously, it was revealed that PWHT of precipitate-hardened aluminum alloys including solution-treatment and quenching followed by artificial aging resulted in a strength drop, whereas application of only artificial aging without solutionizing enhanced the strength $[18,19]$. During the joining of AA2XXX and AA7XXX, the situation would be more critical, and often kissing bonds, incomplete mixing, and destructive phase evolutions are reported [20]. Badini et al. [21] studied the effect of PWHT on laser beam welding of AA2XXX to AA7XXX and revealed that during heat treatment, a lot of $\mathrm{Al}-\mathrm{Cu}-\mathrm{Zn}$ particles were formed in the weld that were prone to pitting in corrosive media. Zhang et al. [22] probed the FSW of AA2024AA7075 and subsequent PWHT. They indicated that due to lack of penetration between the adjacent alloys and the formation of a kissing bond, applying PWHT could not improve the mechanical strength, and the joint eventually failed from primary weak adhesion. Cerri and Leo [23] applied PWHT to the AA2024-AA7075 FSW joint and demonstrated that $\mathrm{PWHT}$ at temperatures higher than $450{ }^{\circ} \mathrm{C}$ induced faster kinetics for particle coarsening and grain growth, and reduced the strength of the weld-line. A similar result was also reported by Huang et al. [24] Later, Bugarin et al. [25] analyzed the BM and thermomechanically affected zone (TMAZ) of AA2024-AA7475 on AA7475-side using TEM and revealed that by moving from BM toward the SZ, the grain boundaries (GBs) and the triple junctions were significantly occupied by the particles enriched with $\mathrm{Cu}, \mathrm{Zn}$, and $\mathrm{Mg}$ elements. The compositional measurement revealed that most of those particles had an $\mathrm{Mg}_{2} \mathrm{Zn}$ arrangement. Zaman Khan et al. [26] and Niu et al. [27] have also reported similar results on AA2219-AA7475 and AA2024-AA7075 joints, respectively. According to their observation, some $\mathrm{Zn}, \mathrm{Mg}$, and $\mathrm{Cu}$-rich $\theta$ and $\mathrm{T}$ phases were formed at the GBs on the AA7475 side of the SZ. Zhang et al. [28] performed EBSD analyses of the FSW joints of AA2024-AA7075 and documented that the AA7475 side had higher residual stress and more intensive texture. With respect to the particle's evolutions in AA2XXXAA7XXX joints, it seems that AA7XXX is more prone to the nucleation and coarsening of precipitates during PWHT of such dissimilar joints. However, previous studies on the FSW of AA7XXX shed light on this issue and revealed a considerable amount of $\mathrm{Mg}_{2} \mathrm{Zn}$ particles settled in the GBs during FSW and subsequent PWHT of the alloys of AA7085 [29], AA7075 [30], and AA7449 [31]. Rather similar particles were also observed in dissimilar joints of AA2XXX-AA6XXX [32,33]. 
The FSW parameters and PWHT conditions were optimized for different dissimilar joints between the AA2XXX to the AA7XXX [34,35] and AA6XXX series [36]. In the meantime, the effect of solution treatment on the dissimilar FSW of AA2198-T3 and AA7475$\mathrm{W}$ has been recently investigated in terms of microstructural and phase transformation analysis [37]. However, no research has yet focused on a comparative study of AA2198AA7475 and AA2198-AA6013 dissimilar joints during the PWHT. This research focused on the phase evolutions in the welding zone of AA2198-AA7475 and AA2198-AA6013 dissimilar joints and tried to explore the origin of weak bonding in AA2198-AA7475 welds that resulted in sudden failure during solution treatment.

\section{Materials and Methods}

The sheets used in the present study were 2-mm-thick AA2198-T6, AA7475-W, and AA6013-T4 sheets. The chemical composition of the employed alloys is listed in Table 1.

Table 1. Chemical composition of the aluminum sheets used in current study.

\begin{tabular}{ccccccc}
\hline Alloy & Al & Cu & Mg & Zn & Si & Fe \\
\hline AA2198 & 96.27 & 3.03 & 0.70 & - & - & - \\
AA7475 & 90.45 & 1.47 & 3.35 & 4.74 & - & - \\
AA6013 & 96.87 & 1.00 & 1.81 & - & 0.24 & 0.09 \\
\hline
\end{tabular}

The tool had a shoulder diameter, pin diameter, and pin height of $13.45,4.70$, and $3.16 \mathrm{~mm}$, respectively. In addition, the advance angle, travel speed, and rotational rate of the tool were $2^{\circ}, 50 \mathrm{~mm} \mathrm{~min}^{-1}$, and $830 \mathrm{rpm}$, respectively. The FSWed sheets were solution-treated at four different temperatures of $460,500,540,560$, and $580{ }^{\circ} \mathrm{C}$ for $1 \mathrm{~h}$ in a conventional furnace and eventually air-cooled at room temperature. To perform the microstructural analysis, the cross-section of samples perpendicular to the weld traverse line were sectioned and mechanically polished. To reveal the microstructure through the optical microscope (OM) and scanning electron microscopy (SEM), the as-polished surface of the specimens was chemically etched with Barker's solution for $10 \mathrm{~s}$. Phase transformations at GBs as well as the failure surfaces of the treated samples were inspected by SEM.

\section{Results and Discussion}

Variation of grain morphology along the weld line of AA2198-AA7475 after solution treatment at different temperatures is demonstrated in Figure 1.

As shown, in the as-weld sample, the stir zone surface and the underpin area, which were in direct contact with the shoulder and tool pin, had the finest grains. Upon treatment at $460{ }^{\circ} \mathrm{C}$, grain growth onset occurred in these severely strained regions and continued toward the center of SZ. Due to the higher kinetic of annealing at $500{ }^{\circ} \mathrm{C}$, most of the grains on the AA7475 side of the SZ were dissolved in the grown grains. However, solution treatments at 540 and $560{ }^{\circ} \mathrm{C}$ were so effective that apart from the complete dissolution of the fine grains in coarser ones, most of the elongated grains in BMs were also recrystallized. Nevertheless, the formation of some interfacial phases vulnerable to corrosive media at GBs of AA7475 resulted in obvious intergranular corrosion in AA7475 during etching. Furthermore, the creation of a distinct boundary/interface in the SZ of the AA7475-AA2198 joint can be attributed to the kissing bond and immiscibility of the BMs [38]. According to grains' evolution, the zones that possess finer grains in the as-weld state experienced the most growth during the solution treatment. Hence, the under-shoulder area contained the largest grains in the solutionized specimens. Apparently, annealing at $580{ }^{\circ} \mathrm{C}$ has resulted in the failure of the joint starting from the AA2198 side due to significant debonding of the grains. To discover and to compare the contribution of solute elements in such an intergranular failure during PWHT of AA2198-AA7475, the dissimilar joint of AA2198AA6013 was exposed to similar solution treatment. The changes in grain morphology during the PWHT of the AA6013-AA2198 joint is presented in Figure 2. 
As can be seen in Figure 2, despite the grains' evolutions in the AA7475-AA2198 weld, annealing at $460{ }^{\circ} \mathrm{C}$ led to grain growth all over the SZ. The solution treatment at higher temperatures up to $540{ }^{\circ} \mathrm{C}$ increased the growth rate in SZ, which resulted in coarser grains, while the BMs were still thermally stable. Annealing at $560{ }^{\circ} \mathrm{C}$ led to the recrystallization of the elongated grains in BMs. Evidently, despite the coarsening of the grains in SZ, solution treatment at elevated temperatures $\left(<580{ }^{\circ} \mathrm{C}\right)$ did not terminate the debonding of the grains. In other words, the welded sheets had desirable cohesion in the SZ (weld interface) even after annealing at $560{ }^{\circ} \mathrm{C}$. However, annealing at $580{ }^{\circ} \mathrm{C}$ was followed by the failure of the joint by the grain dissociation mechanism from the AA2198 side. High-magnification characterization of different welding zones in both dissimilar joints shed light on the origin of such intergranular failure.

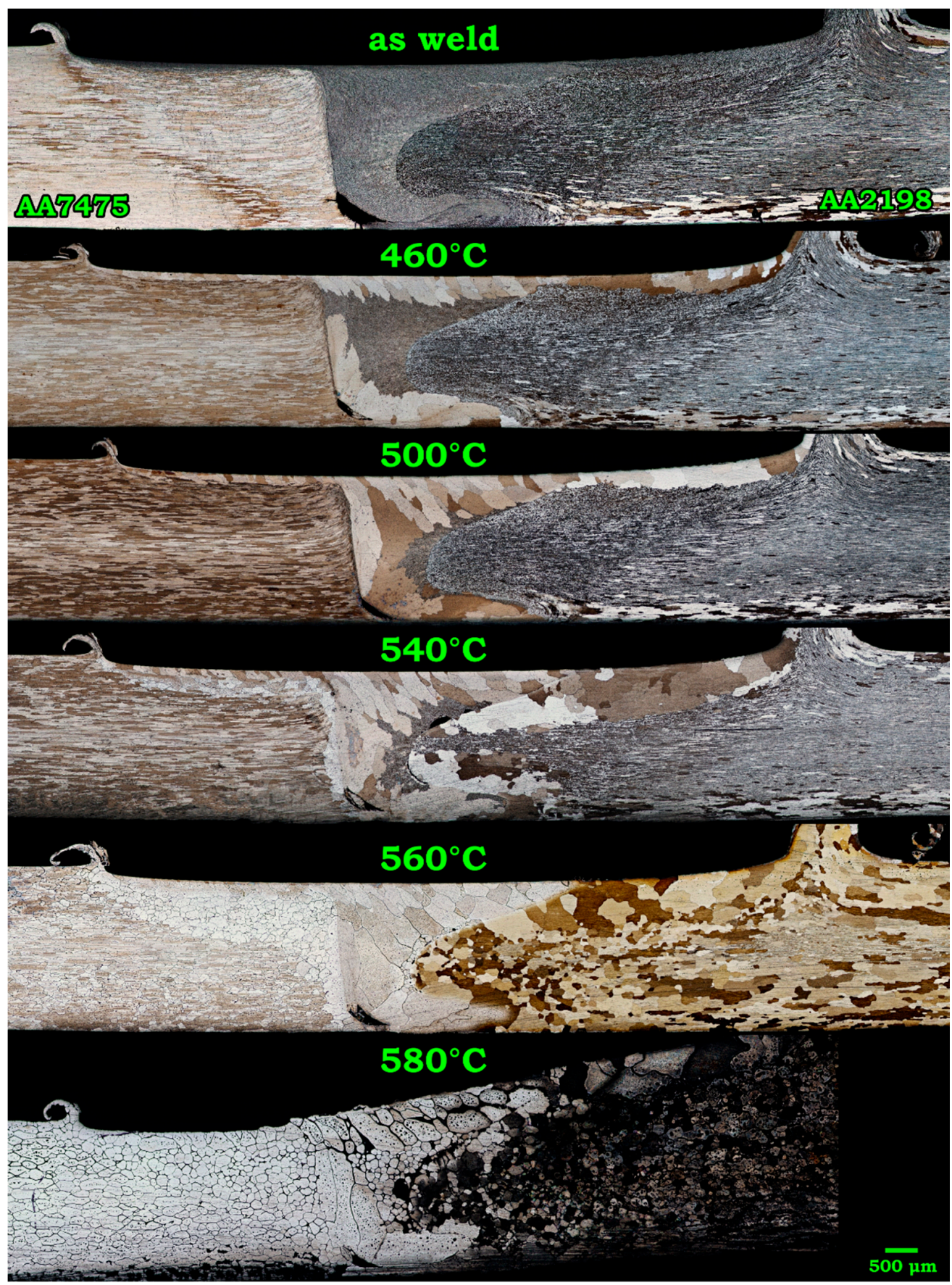

Figure 1. Optical micrograph of AA7475-AA2198 weld after treatment at 460 to $580{ }^{\circ} \mathrm{C}$ for $1 \mathrm{~h}$. 


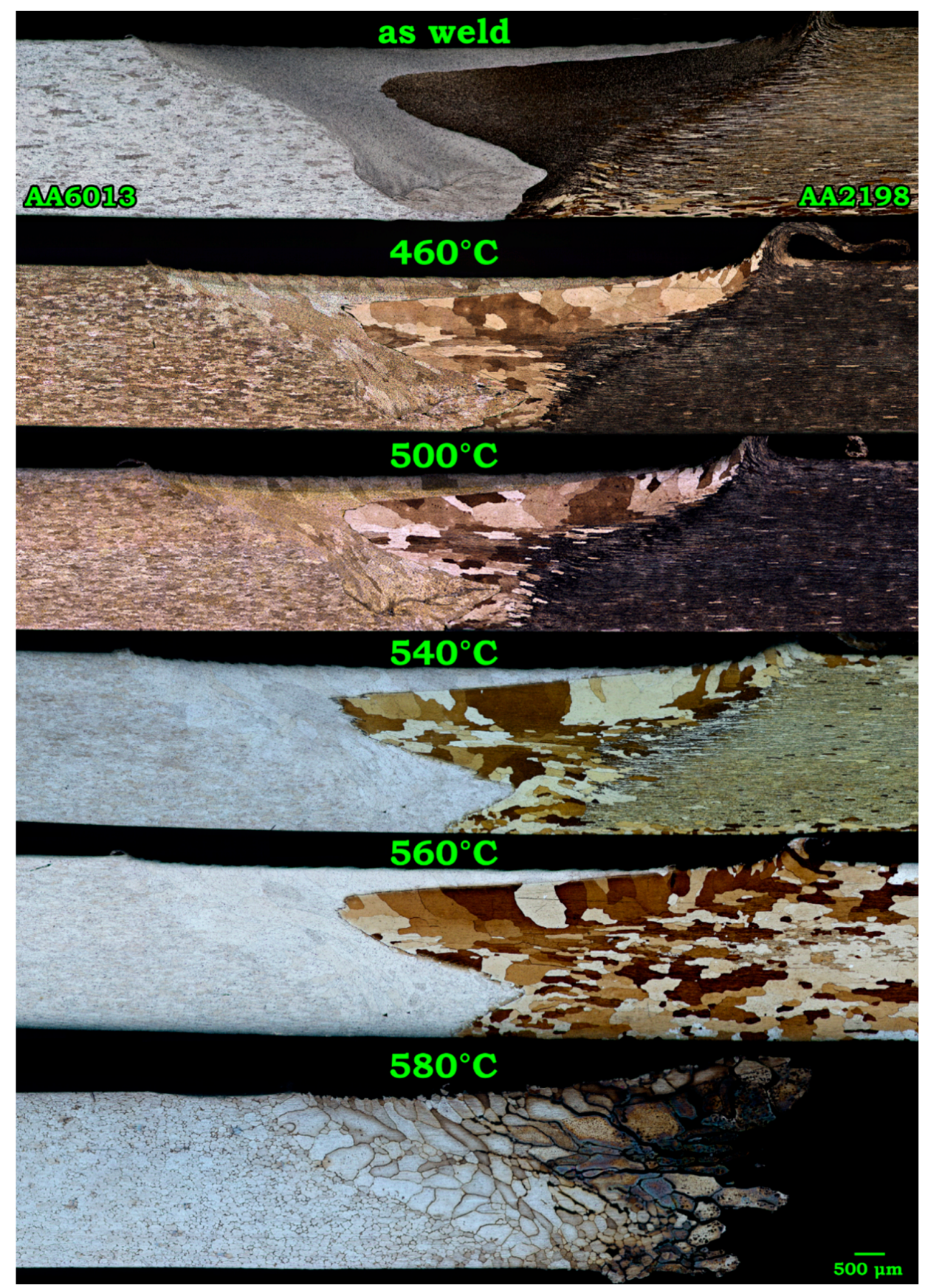

Figure 2. Microstructure evolution in the as-weld AA6013-AA2198 specimen subjected to annealing at $460-580{ }^{\circ} \mathrm{C}$.

SEM micrographs of Figure 3 illustrate the grain morphology and distribution of particles and solute elements in the dissimilar weld lines. According to Figure 3a, SZ had finer grains and particles compared to adjacent areas (HAZ and BM). Figure $3 \mathrm{~b}$ reveals that regardless of composition, the particles in the SZ are fragmented due to the severe turbulence of the material in a semi-solid state around the pin. Figure $3 \mathrm{c}$ shows that both the grains and particles were elongated in the BM of AA2198. The elemental map distribution in the welding interface of AA7475-AA2198 adequately displays the Mg and Zn enrichment on AA7475 and Cu enrichment on the AA2198 side of the welding border. Figure 3d-f exhibits the SEM images and elemental distribution around the welding interface of the as-weld AA6013-AA2198 specimen. A comparison of particle distribution in AA2198 and AA6013 indicated that more particles were present in the AA2198 side of the joint. 
According to the elemental map distribution at the welding interface, $\mathrm{Mg}$ and $\mathrm{Si}$ were the main solute elements in AA6013, while AA2198 was enriched by Cu solute atoms.

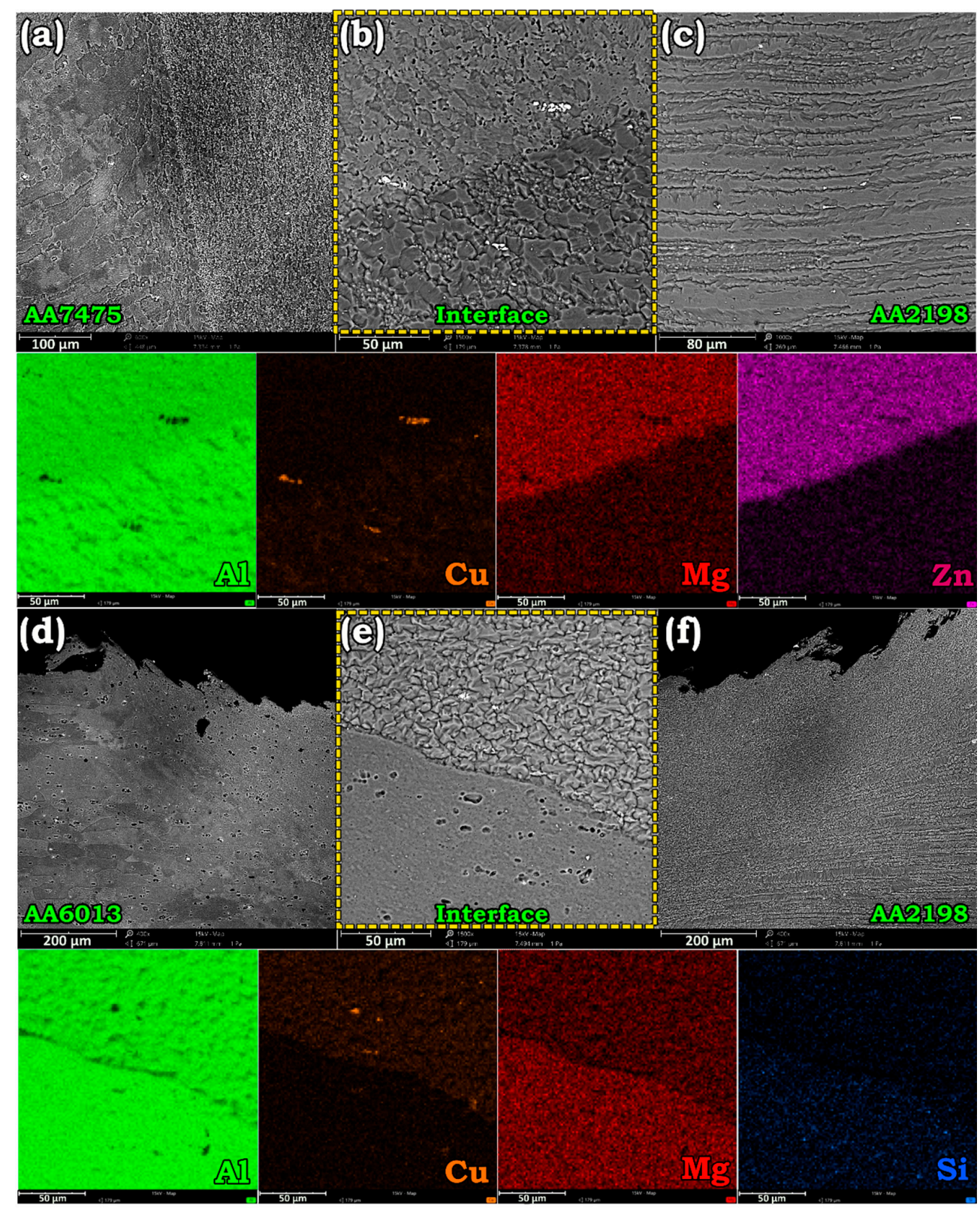

Figure 3. SEM images exhibiting the grain morphology, particle distribution, and maps of constituent elements at welding interface of the AA7475-AA2198 (a-c) and AA6013-AA2198 (d-f) as-weld specimens.

As mentioned, by annealing below $560{ }^{\circ} \mathrm{C}$ for $1 \mathrm{~h}$ some fine grains remained, and grain growth was not yet comprehensive. Nonetheless, SEM analysis of Figure 4 revealed that atomic diffusion parallel to the grain growth led to the formation of some phases at GBs and welding interface. It is well understood that during high-temperature annealing, GBs and triple junctions start to remelt at a temperature below the standard melting point of the alloy: so-called GB premelting/wetting. Premelting of the GBs provides molten paths for the diffusion of the alloying elements with higher kinetics compared to the intragranular diffusion [39-41]. As a result, solute atoms will find a chance to diffuse to the GBs and form complex phases. The elemental analysis of Figure 4a along with line-scan of Figure $4 \mathrm{~b}$ implies the formation of a brittle Cu-rich eutectic phase at GBs of AA7475 in SZ after annealing at $540{ }^{\circ} \mathrm{C}$. SEM images of Figure $4 \mathrm{~b}$ display that although this eutectic 
phase preferentially precipitates at the GBs, in some regions it directly nucleates from the aluminum matrix. According to the phase diagram of $\mathrm{Al}-\mathrm{Cu}$ [42], there is a eutectic point at $548.2^{\circ} \mathrm{C}$ and $32.7 \mathrm{wt} . \% \mathrm{Cu}$. When the annealing time and the temperature is high enough (over $540{ }^{\circ} \mathrm{C}$ ), $\mathrm{Cu}$ solute elements in AA7475-AA2198 diffuse to reach the GBs. At GBs, which are similar to a molten channel at such an elevated temperature, stacked $\mathrm{Cu}$ atoms with some $\mathrm{Al}$ atoms from the matrix formed an $\mathrm{Al}-\mathrm{Cu}$ eutectic compound. Figure $4 \mathrm{c}, \mathrm{d}$ are related to AA6013-AA2198 after solution treatment at 460 and $540{ }^{\circ} \mathrm{C}$. Apparently, increasing the annealing temperature expels the alloying elements from the matrix, and this follows by the precipitation of coarser phases at the high energy sites such as welding interface and GBs.

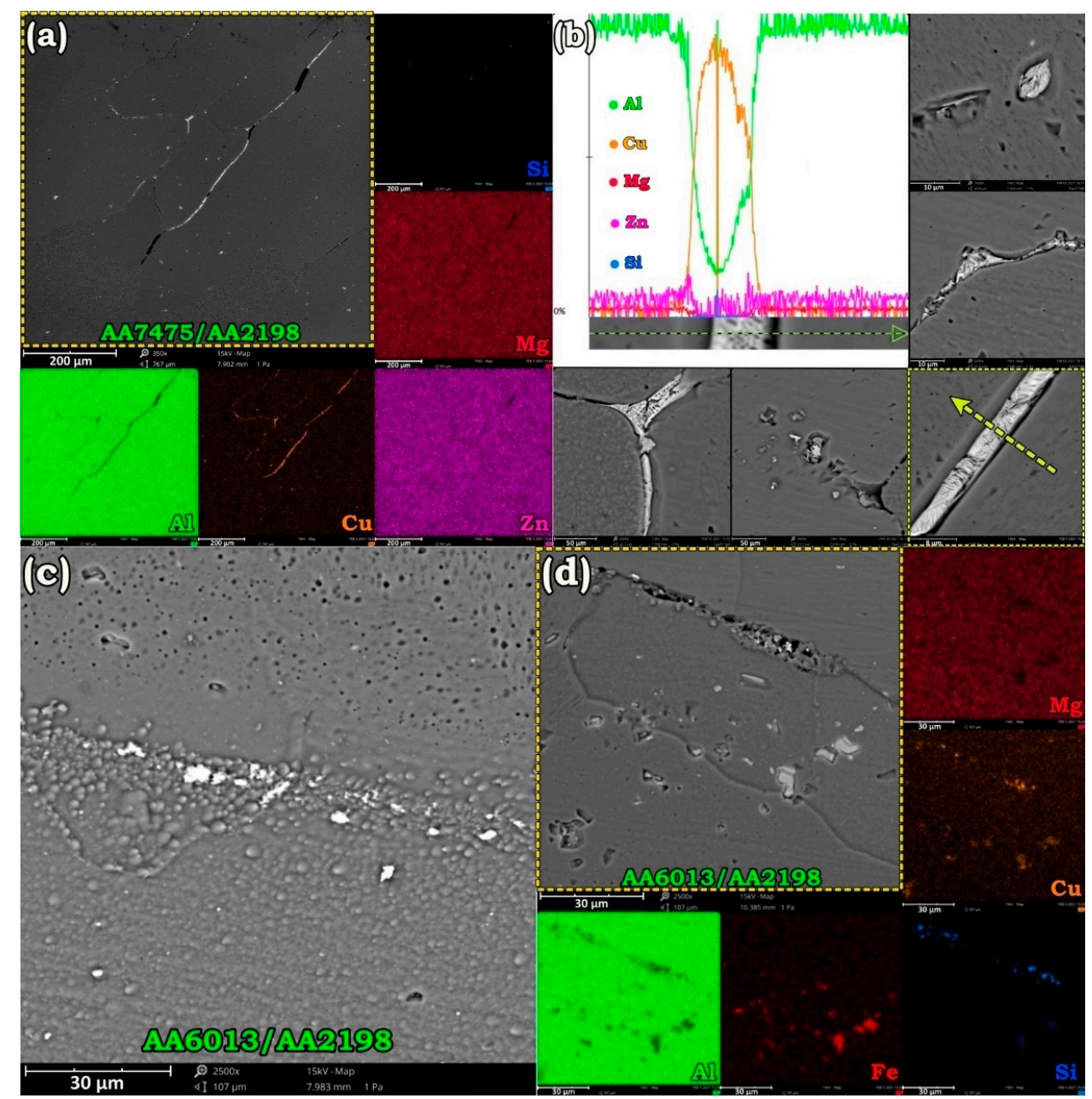

Figure 4. Formation of Al-Cu eutectic phase in AA7475-AA2198 weld specimen by annealing at $540{ }^{\circ} \mathrm{C}(\mathbf{a}, \mathbf{b})$ and second-phase particles around welding interface of AA6013-AA2198 by annealing at $460{ }^{\circ} \mathrm{C}$ (c) and $540{ }^{\circ} \mathrm{C}(\mathbf{d})$.

Increasing the annealing temperature over $540{ }^{\circ} \mathrm{C}$ facilitated the diffusion of atoms to GBs and enhanced the possibility of eutectic phase formation in AA7475-AA2198 specimens. Morphology and distribution of the eutectic phase from BM to SZ of AA7475 are presented in Figure 5. According to Figure 5b-f, which are taken from HAZ and BM regions, after annealing at $580{ }^{\circ} \mathrm{C}$ for $1 \mathrm{~h}$, most of the dissolved $\mathrm{Cu}$ in $\mathrm{Al}$ matrix migrated to the GBs and formed an Al-Cu eutectic phase. Figure $5 \mathrm{~g}$ shows the border of TMAZ/SZ in AA7475 after annealing at $580{ }^{\circ} \mathrm{C}$. Apparently, compared to $\mathrm{BM}$ and $\mathrm{HAZ}$, the Cu-rich phases had different sizes and morphology. Figure 6 targeted the eutectic phases that are formed in the SZ of AA7475. According to Figure $6 \mathrm{a}-\mathrm{c}, \mathrm{Cu}$-rich eutectic phases are spherical in this region. Such a morphology of the eutectic phase can be elucidated by two probable reasons. 
The first is that due to the coarser grains in $\mathrm{SZ}$ after grain growth, atoms must traverse a longer path to reach the GBs. Hence, the $\mathrm{Cu}$ elements tend to diffuse to the closest $\mathrm{Cu}$ colonies and form eutectic islands. On the other hand, as aforementioned, there was a significant difference between the alloying elements on both sides of the welding interface. Hence, annealing at elevated temperatures can facilitate the atomic diffusion to the other side of the interface where the fraction of $\mathrm{Cu}$ near the welding interface was higher than the $\mathrm{HZ}$ and BM of AA7475. Figure 6c adequately proves that these eutectic isolated islands were trapped inside the grains, and due to the shrinkage of the molten phase during air cooling, usually a cavity is formed beside the eutectic phases. Elemental map analyses in Figure 6d,e show that the eutectic phases were mainly composed of $\mathrm{Cu}$, while other alloying elements were accumulated at central regions.
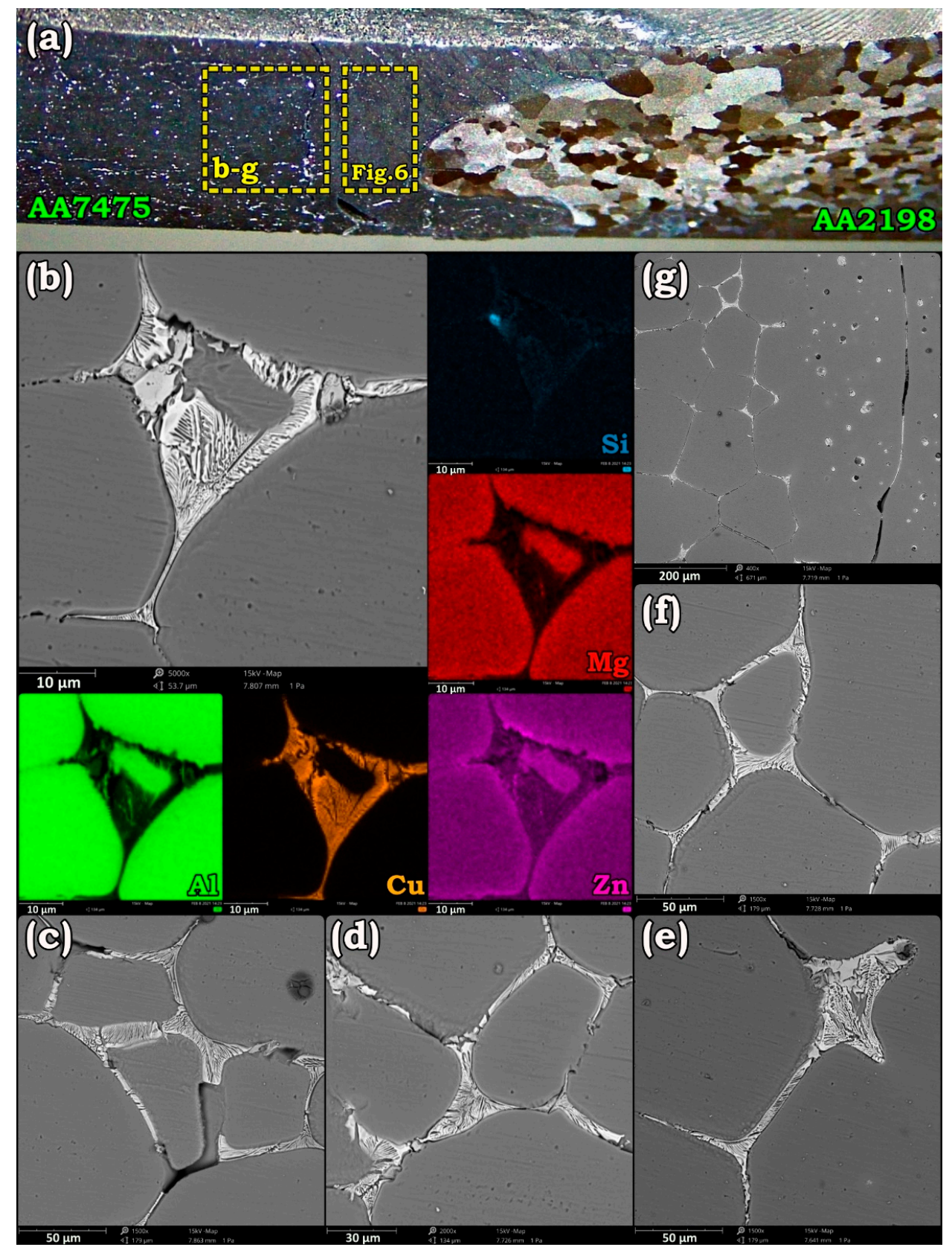

Figure 5. Stereo micrograph of solution treated AA7475-AA2198 sample (a) and formation of Cu-rich eutectic phases at GBs of AA7475 after annealing at $580{ }^{\circ} \mathrm{C}$ for $1 \mathrm{~h}(\mathbf{b}-\mathbf{g})$. 


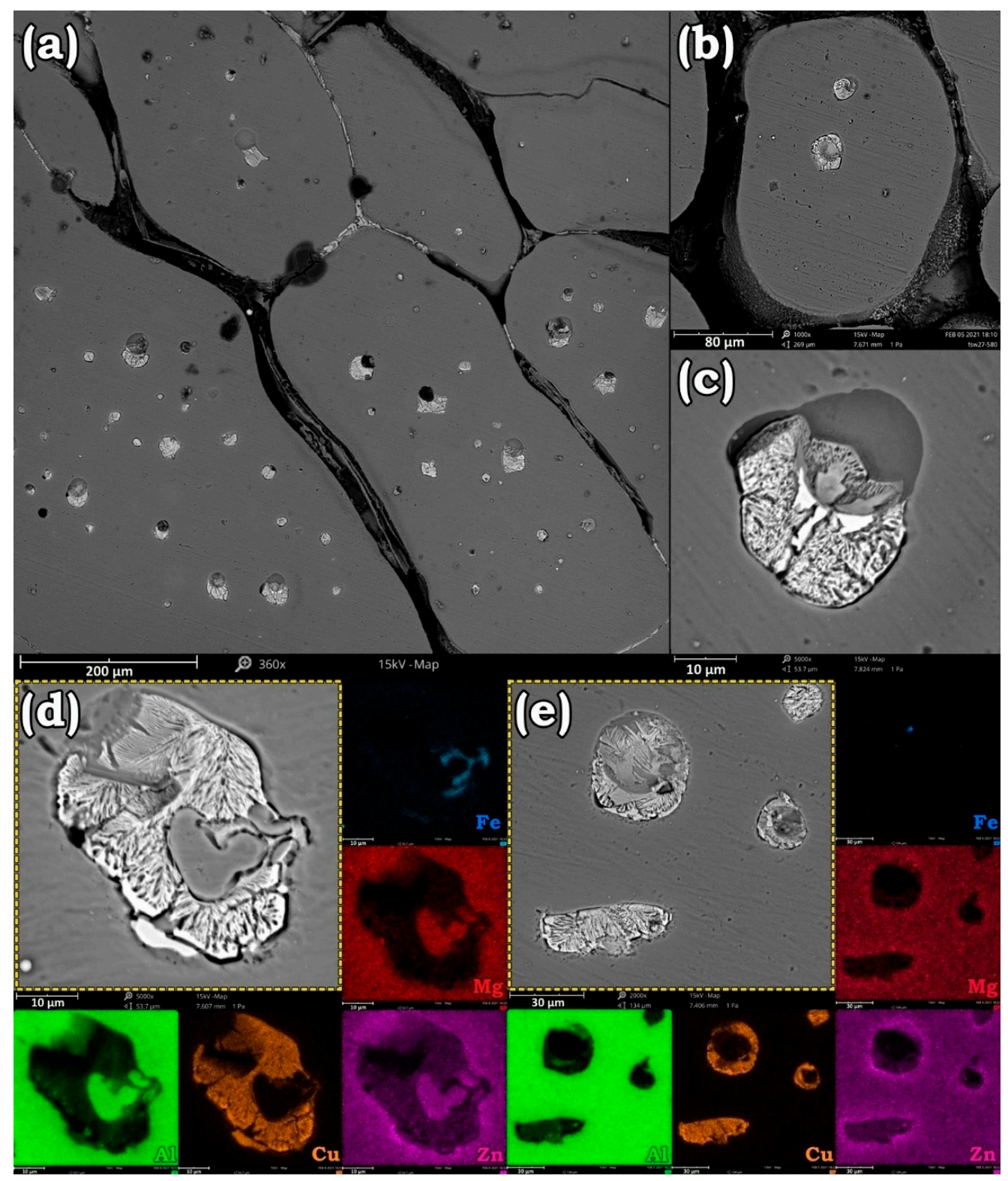

Figure 6. Distribution of intermetallic phases (a), the formation of island-like $\mathrm{Cu}$-rich eutectic phases at the center of the grains $(\mathbf{b}, \mathbf{c})$, and element distribution map of them (d,e) in the stir zone (SZ) of AA7475 after solution treatment at $580^{\circ} \mathrm{C}$ for $1 \mathrm{~h}$.

The phase evolutions in the BM, HAZ, and SZ of the AA6013 after annealing at $580{ }^{\circ} \mathrm{C}$ are exhibited in Figure 7. As can be seen, during high-temperature annealing, most of the alloying elements are diffused to the GBs since $\mathrm{Cu}$ had the most affinity for diffusion toward the boundaries. The SEM images of Figure $7 \mathrm{~b}-\mathrm{d}$ reveal that in BM and HAZ, most of the triple junctions that had minimum pre-melting temperatures were occupied by the brittle $\mathrm{Cu}$-rich compounds. However, some Si- and Fe-rich particles were also formed at the GBs as scattered fine polygonal particles. The SEM micrographs of Figure $7 \mathrm{f}, \mathrm{g}$ are taken from the SZ of AA6013 after annealing at $580^{\circ} \mathrm{C}$. Similar to the observed results for AA7475, the SZ of AA6013 contained stacked elements as islands with more complex constituent phases. Accordingly, $\mathrm{Cu}, \mathrm{Mg}, \mathrm{Si}$, and Fe are the constituent elements of these regions.

To find the origin of intergranular failure after annealing at $580{ }^{\circ} \mathrm{C}$, occupied boundaries with migrated elements were analyzed by microscope and the results are presented in Figure 8. According to Figure $8 \mathrm{a}, \mathrm{b}$ that are taken from the failure edge of the AA7475AA2198 joint, GBs were filled with a Cu-rich eutectic phase in addition to coarse polygonal 
$\mathrm{Zn}$ - and Mg-rich particles. According to the SEM micrographs in Figure $8 \mathrm{c}-\mathrm{h}$, similar accumulation of the solute elements including $\mathrm{Si}$ and Fe occurred at the welding interface of AA6013-AA2198 after annealing at $580{ }^{\circ} \mathrm{C}$. The formation of such massive particles made the weakened GBs by the $\mathrm{Cu}$-rich phases more unstable than before. As a result, even thermal shock and solidification contraction of the molten phases at GBs during air cooling could overcome the weak bonding adhesion between the grains and eventuate in the failure of the joint.

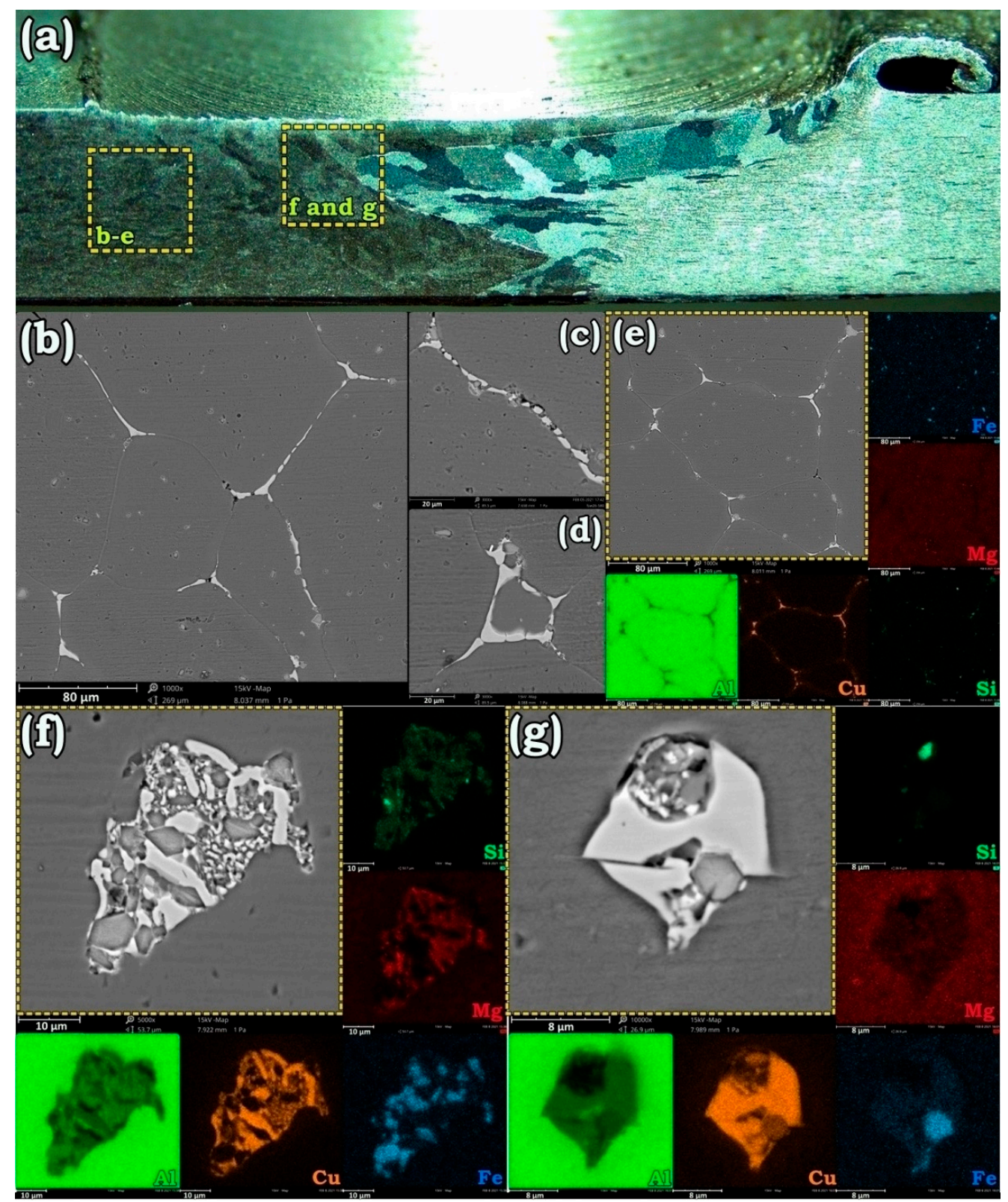

Figure 7. Stereo micrograph of solution treated AA6013-AA2198 weld specimen (a) and SEM micrographs showing the morphology of particles in the the base metals (BM), the heat-affected zone (HAZ) (b-e), and SZ (f,g). along with elemental distribution maps. 


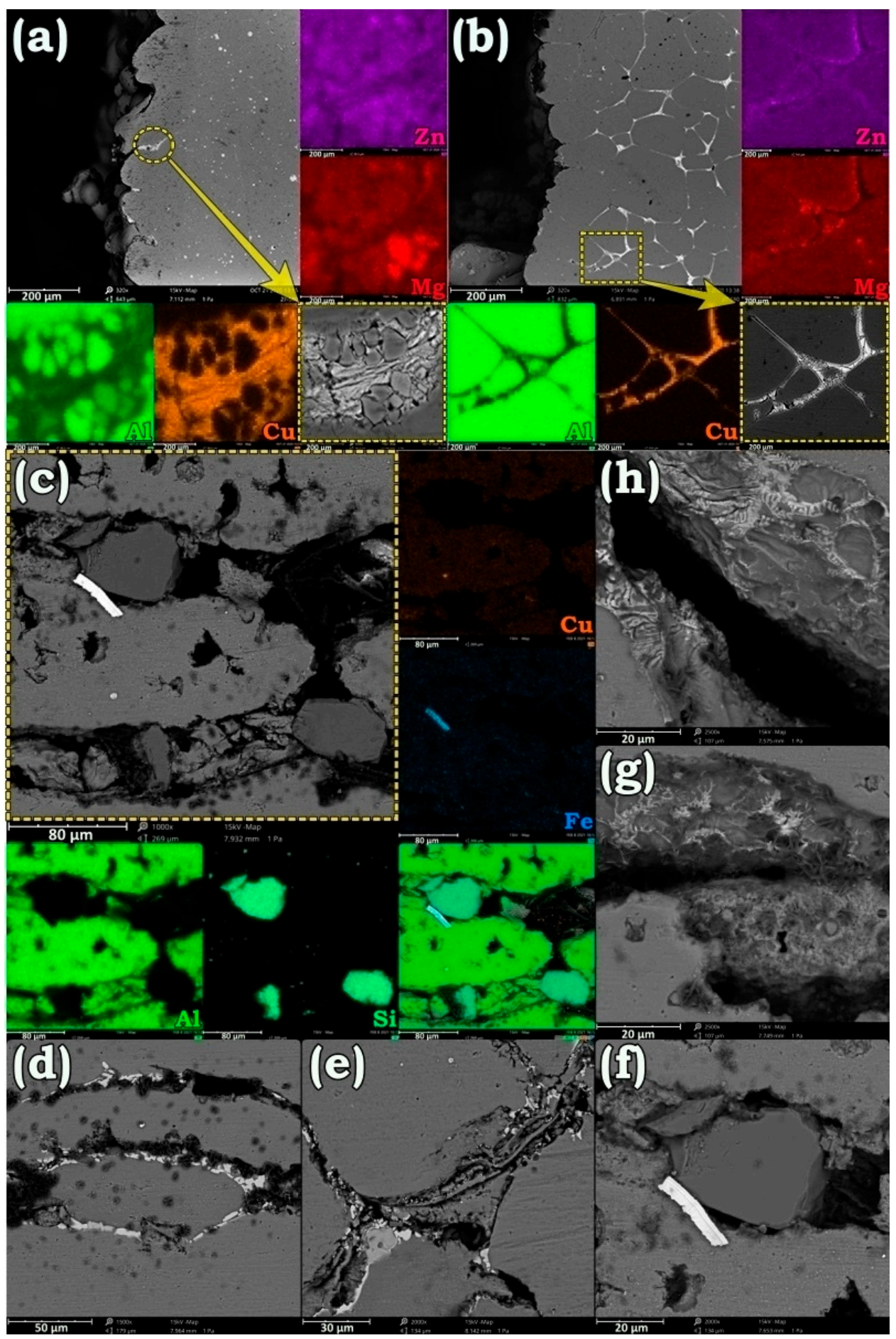

Figure 8. SEM images and elemental map analysis of the phases formed around the failure edge of AA7475-AA2198 (a,b) and AA6013-AA2198 (c-h) welds after annealing at $580{ }^{\circ} \mathrm{C}$ for $1 \mathrm{~h}$.

The failure surface of the AA7475-AA2198 from the TMAZ/SZ interface after annealing at 560 and $580{ }^{\circ} \mathrm{C}$ are presented in Figures $9 \mathrm{a}-\mathrm{f}$ and $9 \mathrm{~g}-\mathrm{i}$, respectively. As can be seen, annealing at such a high-temperature has resulted in substantial grain coarsening, and many of the smaller grains have disappeared at the expense of their bigger counterparts. In the meantime, when the failure occurred, the grains' adhesion was appreciably weak, so that some grains almost lost their cohesion with others. This happens because almost all the GBs were filled with the second-phase particles and white remnants of Cu-rich compounds were precipitated on the surface of the grains (Figure 9a-c). As depicted 
in Figure $9 \mathrm{~d}-\mathrm{f}$, some star-like symmetrical phases were formed at the GBs of the failed specimen. This morphology can be attributed to the directionally uniform heat dissipation while the solidification of the eutectic phase. Therefore, as expected, the accumulation of the eutectic phase played a key role in deboning and separation of the grains (Figure 9h,i). Meanwhile, Figure $9 \mathrm{~g}$ reveals some $\mathrm{Cu}$-rich channels on the surface of the coarse grains that properly show the far $\mathrm{Cu}$ islands from the GBs.

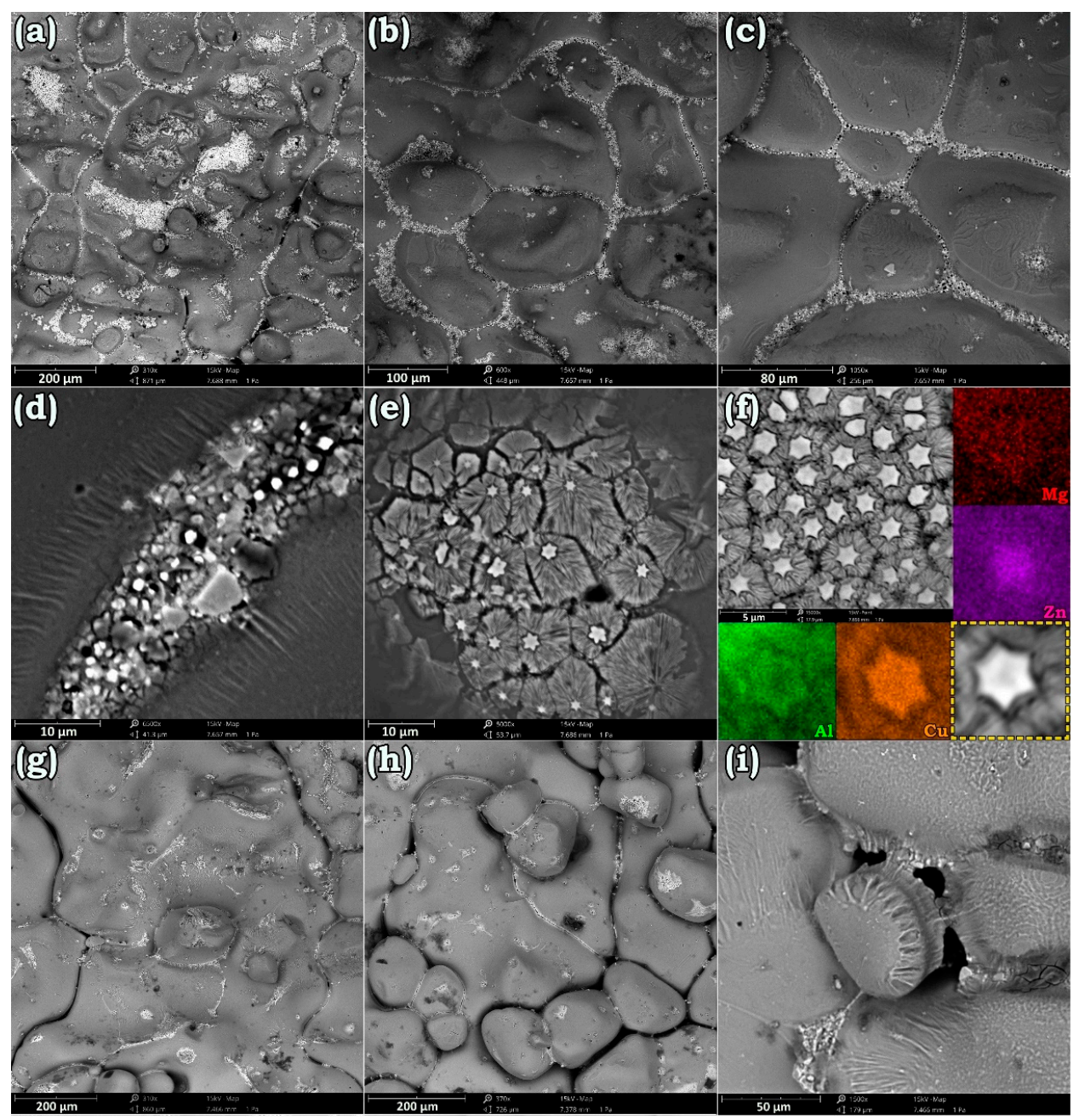

Figure 9. Illustration for the formation of the $\mathrm{Cu}$-rich eutectic phases on the failure surface of the AA7475-AA2198 weld at AA7475 side after annealing at $560{ }^{\circ} \mathrm{C}(\mathbf{a}-\mathbf{f})$ and $580{ }^{\circ} \mathrm{C}(\mathbf{g}-\mathbf{i})$ for $1 \mathrm{~h}$.

\section{Conclusions}

In the current study, the dissimilar joints of AA2198-AA7475 and AA2198-AA6013 underwent solution treatment at $460-580^{\circ} \mathrm{C}$ for $1 \mathrm{~h}$. Thermal treatment over $560{ }^{\circ} \mathrm{C}$ resulted in the failure of both weld specimens from the AA2198 side. Performing a comparative microstructure evolution analysis resulted in the below achievements:

1. By solutionizing, ultrafine grains were the initiation sites for abnormal grain growth within the SZ and experienced the maximum growth during treatment at elevated temperatures. Applying higher temperatures increased the growth rate of the grains and resulted in the disappearance of a higher fraction of fine grains at the expense of coarser ones.

2. Treatment over $540{ }^{\circ} \mathrm{C}$ resulted in pre-melting/wetting of the GBs, and this accelerated the diffusion of the solute atoms to the GBs by the provision of the preferred migration channels. Consequently, for the AA2198-AA6013 specimens, $\mathrm{Cu}, \mathrm{Fe}$, and $\mathrm{Si}$, and additionally in the AA2198-AA7475 joints, $\mathrm{Cu}, \mathrm{Zn}$, and $\mathrm{Mg}$, migrated to the GBs. The 
diffusion of $\mathrm{Cu}$ to the GBs of AA2198 and AA7475 was accompanied by the formation of a Cu-rich eutectic phase, while in AA6013 this led to the formation of Cu-rich brittle particles. However, the diffusion of $\mathrm{Mg}$ and $\mathrm{Zn}$ in AA7475 and the diffusion of Si and Fe in AA6013 led to the formation of coarse polygonal particles at GBs, particularly at triple junctions.

3. After air-cooling of solutionizing over $560{ }^{\circ} \mathrm{C}$, the formation of a remarkable Curich eutectic phase in the pre-melted zones, particularly in AA2198, resulted in intergranular failure due to solidification shrinkage. The formation of $\mathrm{Mg}$ and $\mathrm{Zn}$ particles at the weld interface of the AA7475-AA2198 joints and Si and Fe particles around the welding interface of the AA6013-AA2198 joints contributed to the failure of the weldments.

Author Contributions: Conceptualization, M.R.J., H.P. and M.P.; Formal analysis, H.P.; Investigation, M.R.J., and S.I.H.; Methodology, H.P.; Project administration, M.P.; Resources, A.S.; Supervision, M.P.; Visualization, M.R.J. and A.S.; Writing—original draft, M.R.J.; Writing—review \& editing, H.P., A.S., S.I.H. and M.P. All authors have read and agreed to the published version of the manuscript.

Funding: The authors received no specific funding for this work.

Institutional Review Board Statement: Not applicable.

Informed Consent Statement: Not applicable.

Data Availability Statement: The data that support the findings of this study are available from the corresponding author upon reasonable request.

Conflicts of Interest: The authors declare no conflict of interest.

\section{References}

1. Goel, P.; Mohd, A.W.; Sharma, N.; Siddiquee, A.N.; Khan, Z.A. Effects of Welding Parameters in Friction Stir Welding of Stainless Steel and Aluminum, Advances in Industrial and Production Engineering; Springer: Berlin/Heidelberg, Germany, 2019 ; pp. 815-823.

2. Jandaghi, M.R.; Pouraliakbar, H. Elucidating the microscopic origin of electrochemical corrosion and electrical conductivity by lattice response to severe plastic deformation in Al-Mn-Si alloy. Mater. Res. Bull. 2018, 108, 195-206. [CrossRef]

3. Kashaev, N.; Ventzke, V.; Çam, G. Prospects of laser beam welding and friction stir welding processes for aluminum airframe structural applications. J. Manuf. Process. 2018, 36, 571-600. [CrossRef]

4. Çam, G.; Ipekoğlu, G. Recent developments in joining of aluminum alloys. Int. J. Adv. Manuf. Technol. 2017, 91, 1851-1866. [CrossRef]

5. Guo, Y.; Ma, Y.; Wang, F. Dynamic fracture properties of 2024-T3 and 7075-T6 aluminum friction stir welded joints with different welding parameters. Theor. Appl. Fract. Mech. 2019, 104, 102372. [CrossRef]

6. Zhu, H.; Dong, S.K.; Ma, Z.M.; Wang, J. Study on the Precipitation Behavior of Precipitates of 7075 Aluminum Alloy Friction Stir Welding Joint. Mater. Sci. Forum 2020, 1003, 37-46. [CrossRef]

7. Çam, G.; Mistikoglu, S. Recent Developments in Friction Stir Welding of Al-alloys. J. Mater. Eng. Perform. 2014, $23,1936-1953$. [CrossRef]

8. İpekoğlu, G.; Çam, G. Effects of Initial Temper Condition and Postweld Heat Treatment on the Properties of Dissimilar Friction-Stir-Welded Joints between AA7075 and AA6061 Aluminum Alloys. In Metallurgical and Materials Transactions A; Springer: Berlin/Heidelberg, Germany, 2014; Volume 45.

9. Singh, S.; Dhuria, G. Investigation of post weld cryogenic treatment on weld strength in friction stir welded dissimilar alu-minium alloys AA2014-T651 and AA7075-T651. In Materials Today: Proceedings; Elsevier: Amsterdam, The Netherlands, 2017; Volume 4, pp. 8866-8873.

10. Tao, X.; Chang, Y.; Guo, Y.; Li, W.; Li, M. Microstructure and mechanical properties of friction stir welded oxide dispersion strengthened AA6063 aluminum matrix composites enhanced by post-weld heat treatment. Mater. Sci. Eng. A 2018, 725, 19-27. [CrossRef]

11. Fu, R.-D.; Zhang, J.-F.; Li, Y.-J.; Kang, J.; Liu, H.-J.; Zhang, F.-C. Effect of welding heat input and post-welding natural aging on hardness of stir zone for friction stir-welded 2024-T3 aluminum alloy thin-sheet. Mater. Sci. Eng. A 2013, 559, 319-324. [CrossRef]

12. Malopheyev, S.; Vysotskiy, I.; Kulitskiy, V.; Mironov, S.; Kaibyshev, R. Optimization of processing-microstructure-properties relationship in friction-stir welded 6061-T6 aluminum alloy. Mater. Sci. Eng. A 2016, 662, 136-143. [CrossRef]

13. Khan, N.Z.; Siddiquee, A.N.; Khan, Z.A.; Shihab, S.K. Investigations on tunneling and kissing bond defects in FSW joints for dissimilar aluminum alloys. J. Alloys Compd. 2015, 648, 360-367. [CrossRef]

14. Paidar, M.; Tahani, K.; Vignesh, R.V.; Ojo, O.; Ezatpour, H.; Moharrami, A. Modified friction stir clinching of 2024-T3 to 6061-T6 aluminium alloy: Effect of dwell time and precipitation-hardening heat treatment. Mater. Sci. Eng. A 2020, 791, 139734. [CrossRef] 
15. Khalilabad, M.M.; Zedan, Y.; Texier, D.; Jahazi, M.; Bocher, P. Effect of tool geometry and welding speed on mechanical prop-erties of dissimilar AA2198-AA2024 FSWed joint. J. Manuf. Process. 2018, 34, 86-95. [CrossRef]

16. Pouraliakbar, H.; Khalaj, G.; Jandaghi, M.R.; Fadaei, A.; Ghareh-Shiran, M.K.; Shim, S.H.; Hong, S.I. Three-layered SS321/AA1050/AA5083 explosive welds: Effect of PWHT on the interface evolution and its mechanical strength. Int. J. Press. Vessel. Pip. 2020, 188, 104216. [CrossRef]

17. Khalaj, G.; Pouraliakbar, H.; Jandaghi, M.R.; Gholami, A. Microalloyed steel welds by HF-ERW technique: Novel PWHT cycles, microstructure evolution and mechanical properties enhancement. Int. J. Press. Vessel. Pip. 2017, 152, 15-26. [CrossRef]

18. Wang, J.; Fu, R.; Li, Y.; Zhang, J. Effects of deep cryogenic treatment and low-temperature aging on the mechanical properties of friction-stir-welded joints of 2024-T351 aluminum alloy. Mater. Sci. Eng. A 2014, 609, 147-153. [CrossRef]

19. Widener, C.A. Evaluation of post-weld heat treatments for corrosion protection in friction stir welded 2024 and 7075 alumi-num alloys. Ph.D. Thesis, Wichita State University, Wichita, KS, USA, December 2005.

20. İpekoğlu, G.; Erim, S.; Çam, G. Effects of temper condition and post weld heat treatment on the microstructure and mechani-cal properties of friction stir butt-welded AA7075 Al alloy plates. Int. J. Adv. Manuf. Technol. 2014, 70, 201-213. [CrossRef]

21. Badini, C.; Pavese, M.; Fino, P.; Biamino, S. Laser beam welding of dissimilar aluminium alloys of 2000 and 7000 series: Effect of post-welding thermal treatments on T joint strength. Sci. Technol. Weld. Join. 2009, 14, 484-492. [CrossRef]

22. Zhang, C.; Huang, G.; Zhang, D.; Sun, Z.; Liu, Q. Microstructure and mechanical properties in dissimilar friction stir welded AA2024/7075 joints at high heat input: Effect of post-weld heat treatment. J. Mater. Res. Technol. 2020, 9, 14771-14782. [CrossRef]

23. Cerri, E.; Leo, P. Mechanical properties evolution during post-welding-heat treatments of double-lap Friction Stir Welded joints. Mater. Des. 2011, 32, 3465-3475. [CrossRef]

24. Huang, Y.X.; Wan, L.; Lv, Z.L.; Lv, S.X.; Zhou, L.; Feng, J.C. Microstructure and microhardness of aluminium alloy friction stir welds with heat treatment. Sci. Technol. Weld. Join. 2016, 21, 1-7. [CrossRef]

25. Bugarin, A.; De Abreu, C.; Terada, M.; De Melo, H.; Costa, I. Effect of friction stir welding (FSW) on the electrochemical behav-ior and galvanic coupling of AA2024-T3 and AA7475-T651. Mater. Today Commun. 2020, 25, 101591. [CrossRef]

26. Khan, N.Z.; Ubaid, M.; Siddiquee, A.N.; Khan, Z.A.; Al-Ahmari, A.; Chen, X.; Abidi, M.H. Microstructural features of friction stir welded dissimilar Aluminium alloys AA2219-AA. Mater. Res. Express 2018, 5, 056531. [CrossRef]

27. Niu, P.; Li, W.; Li, N.; Xu, Y.; Chen, D. Exfoliation corrosion of friction stir welded dissimilar 2024-to-7075 aluminum alloys. Mater. Charact. 2019, 147, 93-100. [CrossRef]

28. Zhang, C.; Huang, G.; Cao, Y.; Zhu, Y.; Liu, Q. On the microstructure and mechanical properties of similar and dissimilar AA7075 and AA2024 friction stir welding joints: Effect of rotational speed. J. Manuf. Process. 2019, 37, 470-487. [CrossRef]

29. Delijaicov, S.; Rodrigues, M.; Farias, A.; Neves, M.D.; Bortolussi, R.; Miyazaki, M.; Brandão, F. Microhardness and residual stress of dissimilar and thick aluminum plates AA7181-T7651 and AA7475-T7351 using bobbin, top, bottom, and double-sided FSW methods. Int. J. Adv. Manuf. Technol. 2020, 108, 277-287. [CrossRef]

30. Patta, V.; Reddy, G.; Rao, K. Microstructure, mechanical and corrosion behavior of high strength AA7075 aluminium alloy friction stir welds e Effect of post weld heat treatment. Def. Technol. 2015, 11, 362-369.

31. Sullivan, A.; Kamp, N.; Robson, J.D. Microstructural Evolution in AA7449 Plate Subject to Friction Stir Welding and Post Weld Heat Treatment. Mater. Sci. Forum 2006, 519-521, 1181-1186. [CrossRef]

32. Pabandi, H.K.; Jashnani, H.R.; Paidar, M. Effect of precipitation hardening heat treatment on mechanical and microstructure features of dissimilar friction stir welded AA2024-T6 and AA6061-T6 alloys. J. Manuf. Process. 2018, 31, 214-220. [CrossRef]

33. Moradi, M.M.; Aval, H.J.; Jamaati, R. Effect of pre and post welding heat treatment in SiC-fortified dissimilar AA6061-AA2024 FSW butt joint. J. Manuf. Process. 2017, 30, 97-105. [CrossRef]

34. Nelson, T.; Steel, R.; Arbegast, W. In situ thermal studies and post-weld mechanical properties of friction stir welds in age hardenable aluminium alloys. Sci. Technol. Weld. Join. 2003, 8, 283-288. [CrossRef]

35. Safarbali, B.; Shamanian, M.; Eslami, A. Effect of post-weld heat treatment on joint properties of dissimilar friction stir welded 2024-T4 and 7075-T6 aluminum alloys. Trans. Nonferrous Met. Soc. China 2018, 28, 1287-1297. [CrossRef]

36. Paidar, M.; Vignesh, R.V.; Khorram, A.; Ojo, O.O.; Rasoulpouraghdam, A.; Pustokhina, I. Dissimilar modified friction stir clinching of AA2024-AA6061 aluminum alloys: Effects of materials positioning. J. Mater. Res. Technol. 2020, 9, 6037-6047. [CrossRef]

37. Jandaghi, M.R.; Pouraliakbar, H.; Hong, S.I.; Pavese, M. Grain boundary transition associated intergranular failure analysis at TMAZ/SZ interface of dissimilar AA7475-AA2198 joints by friction stir welding. Mater. Lett. 2020, 280, 128557. [CrossRef]

38. İpekoğlu, G.; Kıral, B.G.; Erim, S.; Çam, G. Investigation of the effect of temper condition on friction stir weldability of AA7075 Al-alloy plates. Mater. Technol. 2012, 46, 627-632.

39. Straumal, B.; Kogtenkova, O.; Zięba, P. Wetting transition of grain-boundary triple junctions. Acta Mater. 2008, 56, 925-933. [CrossRef]

40. Rabkin, E.; Shvindlerman, L.; Straumal, B. Grain boundaries: Phase transitions and critical phenomena. Int. J. Mod. Phys. B 1991, 5, 2989-3028. [CrossRef]

41. Jandaghi, M.; Badini, C.; Pavese, M. Dissimilar friction stir welding of AA2198 and AA7475: Effect of solution treatment and aging on the microstructure and mechanical strength. J. Manuf. Process. 2020, 57, 712-724. [CrossRef]

42. Zobac, O.; Kroupa, A.; Zemanova, A.; Richter, K.W. Experimental Description of the Al-Cu Binary Phase Diagram. Metall. Mater. Trans. A 2019, 50, 3805-3815. [CrossRef] 